Toshiaki Nakajima • Takao Hamakubo

Tatsuhiko Kodama · Johji Inazawa • Mitsuru Emi

\title{
Genomic structure and chromosomal mapping of the human sterol regulatory element binding protein (SREBP) cleavage-activating protein (SCAP) gene
}

\begin{abstract}
Sterol regulatory element binding protein (SREBP) cleavage-activating protein (SCAP) is a central regulator of lipid synthesis and uptake in mammalian cells. The entire genomic structure of the human SCAP gene was cloned in a $110-\mathrm{kb}$ region covered by overlapping genomic clones. The SCAP gene was localized to chromosome 3 p21.3 by fluorescence in situ hybridization. The human $S C A P$ gene is over $30 \mathrm{~kb}$ in length and contains 23 exons and 22 introns. The transcription initiation site within exon 1 is separate from the initiation codon coded in exon 2. Analysis of exon/intron structure revealed that the gene consists of a mosaic of exons encoding functional protein domains. Exon 1 encodes the 5' non-coding region. Exons $2,3,7,8,9,10,11,13$, and 15 , respectively, encode each of the eight transmembrane regions. Of these, exons 7-11 encode the sterol-sensing domain. Exons 15-23 encode the hydrophilic carboxyl-terminal domains containing four copies of a motif called the Trp-Asp (WD) repeats that interact with and regulate SREBP and the site-1 protease. Sequence analysis of the $5^{\prime}$-flanking region showed that it comprised a high $\mathrm{G} / \mathrm{C}$-rich region and contained adipocyte determination and differentiation-dependent factor 1 (ADD1)/ SREBP-1 binding sites in addition to Sp1 and AP2 sites. This suggests that $S C A P$ gene expression is under the control of SREBP-1, a key regulator of the expression of genes essential for intracellular lipid metabolism. Our data establish the basis of investigation for molecular variants in this gene that may result in alterations in plasma lipoprotein levels and/or derangement of intracellular lipid metabolism.
\end{abstract}

T. Nakajima $\cdot$ M. Emi $(\bowtie)$

Department of Molecular Biology, Institute of Gerontology, Nippon

Medical School, 1-396 Kosugi-cho, Nakahara-ku, Kawasaki 211-8533, Japan

Tel. +81-44-733-5230; Fax +81-44-733-5192

e-mail: memi@nms.ac.jp

T. Hamakubo · T. Kodama

Department of Molecular Biology and Medicine, Research Center for Advanced Science and Technology, University of Tokyo, Tokyo, Japan

J. Inazawa

Medical Research Institute, Tokyo Medical and Dental University,

Tokyo, Japan
Key words SREBP cleavage-activating protein (SCAP) sterol regulatory element binding proteins (SREBPs)

\section{Introduction}

Sterol regulatory element binding protein (SREBP) cleavage-activating protein (SCAP) is a central regulator of lipid synthesis and uptake in mammalian cells (Hua et al. 1996; Brown and Goldstein 1997). Located in the endoplasmic reticulum, SCAP stimulates the proteolytic cleavage of sterol regulatory element binding proteins (SREBPs) that activate the synthesis of cholesterol and fatty acids and their uptake from plasma via the low-density lipoprotein (LDL) receptor. SCAP-stimulated proteolysis releases active fragments of SREBPs from the membranes of the endoplasmic reticulum and allows them to enter the nucleus, where they activate the transcription of target genes involved in intracellular lipid homeostasis. The activity of SCAP is abolished by increases in sterols, a regulatory mechanism that maintains the constant lipid composition of cell membranes.

Point mutations in the sterol-sensing domain of SCAP were previously shown to cause resistance to sterol suppression (Hua et al. 1996; Nohturfft et al. 1998). Cells with a point mutation continue to synthesize cholesterol and to take up LDL even when they are massively overloaded with sterols. Transgenic mice that expressed this type of mutant SCAP in their livers developed enlarged livers that were engorged with cholesterol and triglycerides (Korn et al. 1998).

Given the central role of SCAP in the regulation of lipid metabolism, molecular variants in the human $S C A P$ gene would likely result in alterations in plasma lipoprotein levels and/or derangement of lipid metabolism within tissue. As a first step in determining whether molecular variants in the $S C A P$ gene contribute to human disease, we determined the gene structure and chromosomal localization of the human $S C A P$ gene. 


\section{Material and methods}

\section{Cloning of full-length $S C A P$ cDNA}

In order to obtain the full-length cDNA sequence, we carried out 5' rapid amplification of cDNA ends (5' RACE) experiments using the partial SCAP cDNA sequence, KIAA0199, deposited in the GenBank database under accession no. D83782 (Nagase et al. 1996). 5' RACE was performed using a Marathon cDNA amplification kit (Clontech, Palo Alto, CA, USA). In brief, human poly(A) RNA from a human hepatoma cell line, SKHep1 (ATCC HTB-52, Rockville, MD, USA), was first reverse-transcribed with Avian Myeloblastosis Virus (AMV) reverse transcriptase, using oligo(dT) primer. The second-strand cDNA was synthesized with T4 DNA polymerase from this single-strand cDNA, and the Marathon cDNA adapter was ligated. The adapterligated cDNA was subjected to two rounds of polymerase chain reaction (PCR), as follows. The first PCR was performed using a combination of an outer adapter primer (AP1) and a gene-specific primer, 5'-GAAGTCTGCAGGGTTTTAGGCTCGT-3', that corresponds to nucleotides 209-234 of the human partial SCAP cDNA sequence, KIAA0199 (Nagase et al. 1996). An aliquot of the first PCR reaction mixture was used as a template for nested PCR, carried out with a combination of a nested adapter primer (AP2) and a nested gene-specific primer, 5'-TCAGTAGGCTCTCCTTGTTTGCGGT-3' that corresponds to nucleotides 588-612 of the human partial SCAP cDNA sequence. The PCR products were resolved by electrophoresis in a $1 \%$ agarose gel and the specific PCR product, visualized by ethidium-bromide staining, was purified using a Gel Extraction Kit (QIAGEN, Tokyo, Japan). The nucleotide sequence of the cDNA was determined by the BigDye Terminator cycle sequencing method, using a 377 ABI Prism automated DNA sequencer (Perkin-Elmer, Norwalk, CT, USA).

\section{Isolation of the human $S C A P$ gene}

A bacteriophage P1-derived artificial chromosome (PAC) library containing human genomic DNA pooled in a threedimensional structure (Genome Systems, St. Louis, MO, USA) was used for the isolation of human SCAP genomic clones. The three-dimensional PAC library was screened by PCR by a method described previously (Tsukamoto et al. 1998), using two oppositely oriented oligonucleotides (forward: 5'-TGGGGATGTCACCTCCCTTAC-3' and reverse: 5'-TGCTGAATGGAGTAGAACTTGATGC-3') that correspond to nucleotides 3476-3495 and 3564-3588 of the human partial SCAP cDNA sequence, KIAA0199. Eschericia coli containing the positive clone was cultured in the presence of ampicillin, and PAC DNA was isolated as described previously (Tsukamoto et al. 1998).

Sequence analysis of exon/intron junctions and the 5 '-flanking region of the $S C A P$ gene

Nucleotide sequences of exons and their boundaries were determined by directly sequencing the PAC clone, using primers designed from the partial $S C A P$ cDNA sequence, KIAA0199 (Nagase et al. 1996) (Table 1). Primers for sequence analysis of the 5 '-flanking region and exon/intron junction of exon 1 were designed from the nucleotide sequence of full-length SCAP cDNA obtained by 5' RACE. Sequencing was performed by the BigDye Terminator cycle sequencing method, using a 377 ABI Prism automated DNA sequencer (Perkin Elmer). The size of each intron was determined by direct sequencing of the PAC genomic clone or estimated by PCR amplification, using LA Taq (Takara, Tokyo, Japan), of each intron, using two oppositely oriented primers located in two exons flanking each intron .

Chromosomal mapping of the human SCAP gene by fluorescence in situ hybridization (FISH)

To assign the SCAP gene location on human chromosomes, a PAC clone carrying the human PAC chromosomal gene was used as a probe. Fluorescence in situ hybridization was carried out as described (Mukae et al. 1998). The cosmid DNA was labeled with biotin-16-deoxyuridine triphosphate dUTP by nick-translation and hybridized to the denatured chromosomes, at a final concentration of $25 \mathrm{ng} / \mathrm{ml}$, in $50 \%$ formamide, $10 \%$ dextran sulfate, $2 \times$ saline-sodium citrate, $0.2 \mathrm{mg} / \mathrm{ml}$ Cot-1 DNA (GIBCO/BRL, Frederick, MD, USA), $2 \mathrm{mg} / \mathrm{ml}$ salmon sperm DNA, and $2 \mathrm{mg} / \mathrm{ml} \mathrm{E}$. coli tRNA. The hybridized signals were detected with fluorescein isothiocyanate-avidin (Boehringer Mannheim, Indianapolis, IN, USA). Metaphase cells were counterstained with 4',6-diamidino-2-phenylindole, and the slides were examined through a Nikon epifluorescent microscope equipped with a change-coupled device (CCD) camera (Photometrics, Tucson, AZ, USA). Images were captured with Quips (Vysis) software and processed with Adobe Photoshop 3.0 software (Adobe Systems).

\section{Results and discussion}

\section{Characterization of the $5^{\prime}$ region of $S C A P$ cDNA}

The nucleotide sequence of the partial human SCAP cDNA sequence, KIAA0199, previously described by Nagase et al. (1996), lacked the 5' untranslated region (UTR), a translation initiation codon, and the $5^{\prime}$ portion of the open reading frame (ORF). We thus carried out 5' RACE experiments and determined the full-length sequence of human $S C A P$ cDNA. The 5'-RACE experiments yielded an additional $144 \mathrm{bp}$ of cDNA sequence on the $5^{\prime}$ end of the partial human SCAP cDNA sequence, KIAA0199 (Fig. 1A). It was thus determined that human full-length $S C A P$ cDNA consists of $139 \mathrm{bp}$ of $5^{\prime} \mathrm{UTR}, 3840 \mathrm{bp}$ of coding region, and $141 \mathrm{bp}$ of $3^{\prime}$ UTR. The sequence around the SCAP initiation codon was "GAGGATGA", which appears to be a variant of an initiator consensus sequence "G/ANNATGG", as proposed in Kozak's initiation rule (Kozak 1987). 
Table 1. Exon/intron organization of the human $S C A P$ gene

\begin{tabular}{|c|c|c|c|c|}
\hline \multirow{2}{*}{$\begin{array}{l}\text { Exon } \\
\text { number }\end{array}$} & \multirow{2}{*}{$\begin{array}{l}\text { Exon } \\
\text { size } \\
\text { (bp) }\end{array}$} & \multicolumn{2}{|l|}{ Sequence at exon/intron junction ${ }^{\mathrm{a}}$} & \multirow{2}{*}{$\begin{array}{l}\text { Intron } \\
\text { size }^{b} \\
\text { (bp) }\end{array}$} \\
\hline & & 5' Splice donor & 3' Splice acceptor & \\
\hline 1 & 44 & GCCACCACAGgtaccgacacı•• & •••ttcttaccagGTACCTGCAC & ND \\
\hline 2 & 220 & TAGCCTGCTGgtatgttttt॰•• & •••tacatcccagCTACCCACTG & $8,300 *$ \\
\hline 3 & 130 & GCCTGAGTGGgtgggtactc••• & •••tcttctgcagTATGTGGGTG & $10,000 *$ \\
\hline 4 & 158 & TGAGAGACAGgtaccectctø•• & •.otcctgtgcagCTCTGGGATC & $800 *$ \\
\hline 5 & 221 & ACACTCAAAGgtagccccagø•• & •••ctgcttgcagACTTGTTATT & 184 \\
\hline 6 & 106 & ACCATGCCAAgtaagattga॰•• & •••cttgaccagGTTCCTGGGC & $1,000 *$ \\
\hline 7 & 173 & TTCTCCACGCgtaggttcat••• & $\bullet \bullet \bullet t g c c c t c c a g G G A A G A T C G A$ & $400 *$ \\
\hline 8 & 127 & TCAATGGCGGgtaggtccet॰•• & •••ttgtccccagCGAGATTTTC & $1,400 *$ \\
\hline 9 & 113 & ATCGCCCAAGgtaacgcagtı•• & $\bullet \bullet \cdot c c t c t g c a g G C C T A A G C A G$ & $1,300 *$ \\
\hline 10 & 95 & CGCCATCCAGgtaaggeccc॰•• & ••ctgattccagGAGTTCTGTC & $1,400 *$ \\
\hline 11 & 99 & CCGGATGGAGgtaggagtgg••• & $\bullet \bullet c c c c c a a c a g$ CTAGCAGACC & 158 \\
\hline 12 & 219 & CCTCATCATGgtacctgcca••• & •••cccactgcagGCTGGCACCG & $800 *$ \\
\hline 13 & 377 & TGGCCAAGAGgtgagctggg••• & •••ccgaatccagGTACATCAGC & $500 *$ \\
\hline 14 & 189 & CGCTGTACAAgtaaggctgc॰•• & •••tccegtgcagGGTGGCGGCG & 132 \\
\hline 15 & 202 & CCACCTCATGgtgagcagggø•• & $\bullet \bullet g c t t c t g c a g G A C A T C G A G T$ & 72 \\
\hline 16 & 116 & CGCGCCCAGGgtaggtgcgg••• & 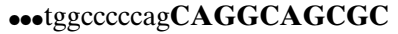 & ND \\
\hline 17 & 523 & CCGGCTGGAGgtgggcagag••• & •••ggactcgtagGTGTGGGACG & 96 \\
\hline 18 & 86 & TGGACAAAAGgtgagcgtgg••• & •••tctcttccagGATTGTGGCT & $2,000 *$ \\
\hline 19 & 83 & CAGTTTAGAGgtcggagggc••• & $\bullet \bullet \bullet t t g t c c t c a g G G A C C C C A G G$ & 104 \\
\hline 20 & 167 & CACACTGAGAgtgagtattg••• & •••cctgtcccagGTGTTCCGTC & 174 \\
\hline 21 & 81 & CATTGACCAGgtaagcggcc^•• & $\bullet \bullet \operatorname{etttccccagACCATGGTGC}$ & 185 \\
\hline 22 & 207 & CATTCAGCAGgtagagggga»•• & ••ttgcctccagGACCTGGGCT & 80 \\
\hline 23 & 387 & & & \\
\hline
\end{tabular}

${ }^{a}$ The sequences of exon/intron boundaries were determined as described in Materials and Methods. The lowercase letters refer to intron sequences and the uppercase letters to exon sequences

${ }^{\mathrm{b}}$ The intron sizes were determined by direct sequencing of the PAC genomic clone or estimated by polymerase chain reaction amplification, using LA Taq (asterisks) (Takara). ND, Not determined

Table 2. Oligonucleotides used to define exon/intron junctions of the human SCAP gene

\begin{tabular}{|c|c|c|}
\hline Exon & Oligonucleotide sequence (forward/reverse) & $\begin{array}{l}\text { Nucleotide position }{ }^{\mathrm{a}} \\
\text { in cDNA (forward/reverse) }\end{array}$ \\
\hline 2 & 5'-CCTGACTGAAAGGCTGCGTG-3'/5'-GGGATGGGATAGGATGCACAG-3' & $1-20 / 58-78$ \\
\hline 3 & 5'-AGGACCTGTGGAATTCACCA-3'/5'-TGGTGAATTCCACAGGTCCT-3' & $151-170 / 151-170$ \\
\hline 4 & 5'-TGGCACAAGAACCTCCTGGC-3'/5'-GCCAGGAGGTTCTTGTGCCA-3' & $308-328 / 308-328$ \\
\hline 5 & 5'-AGCTCAGGAACCTACTCCCT-3'/5'-AGGGAGTAGGTTCCTGAGCT-3' & $471-490 / 471-490$ \\
\hline 6 & 5'-ACTTGTTATTTGGTGTTCCTG-3'/5'-TTGGCATGGTAGTGCTGGAAG-3' & $627-647 / 712-732$ \\
\hline 7 & 5'-CAAGGAGGAGATTGGTGTCG-3'/5'-CTCCTCCTTGAAGTGCACGT-3' & $823-842 / 813-832$ \\
\hline 8 & 5'-TGGGACTCTGCACACTCTTCG-3'/5'-CGAAGAGTGTGCAGAGTCCCA-3' & 987-1007/987-1007 \\
\hline 9 & 5'-AATGTGTTGGTGCTCACCAAGTC-3'/5'-GATCCGCAGCTTCACCTCCA-3' & 1073-1095/1119-1138 \\
\hline 10 & 5'-CGAGAGCTGGTCCATCATGAA-3'/5'-ATGAGGATGATGCCCAGCTC-3' & 1156-1176/1190-1209 \\
\hline 11 & 5'-TGTCTGACTTCTTCCTTCAG-3'/5'-CTGAAGGAAGAAGTCAGACA-3' & $1272-1291 / 1272-1291$ \\
\hline 12 & 5'-AGGCTGCGTGTTGTCTACTTC-3'/5'-GAAGTAGACAACACGCAGCCT-3' & $1502-1522 / 1502-1522$ \\
\hline 13 & 5'-GCTACCTGAGAACCAGACGTC-3'/5'-GACGTCTGGTTCTCAGGTAGC-3' & $1753-1773 / 1753-1773$ \\
\hline 14 & 5'-CTCAGGACGGCCGCAGTGCCT-3'/5'-AGGCACTGCGGCCGTCCTGAG-3' & $2009-2030 / 2009-2030$ \\
\hline 15 & 5'-CCTGCGACGACTACGGCTATG-3'/5'-CATAGCCGTAGTCGTCGCAGG-3' & $2256-2276 / 2256-2276$ \\
\hline 16 & 5'-GACATCGAGTGCCTGGCCAGC-3'/5'-CCTGGGCGCGGAATGCGCGTT-3' & $2327-2347 / 2422-2442$ \\
\hline 17 & 5'-AGTGCCGAGGGTTCCATCTG-3'/5'-GTCAATTAAGCAGGTGAGGTC-3' & $2888-2908 / 2888-2908$ \\
\hline 18 & 5'-GTGTGGGACGCCATTGAAG-3'/5'-TTGTCCAAGAACACCAGAGC-3' & 2966-2984/3029-3048 \\
\hline 19 & 5'-GATTGTGGCTGCACGGCTCAA-3'/5'-GACAGGCCACTGTGTCGCTG-3' & $3052-3072 / 3181-3200$ \\
\hline 20 & 5'-CAGCGACACAGTGGCCTGTC-3'/5'-GACAGGCCACTGTGTCGCTG-3' & $3181-3200 / 3181-3200$ \\
\hline 21 & 5'-GTGTTCCGTCTGGAGGACT-3'/5'-TGAATGGAGTAGAACTTGATGC-3' & $3302-3320 / 3564-3588$ \\
\hline 22 & 5'-TGGGGATGTCACCTCCCTTAC-3'/5'-TGAATGGAGTAGAACTTGATGC-3' & $3475-3495 / 3564-3588$ \\
\hline 23 & 5'-TCTGTGCTGGAGAAGCTGGACT-3'/5'-TATTACAGTCAGGAGGCAGCGG-3' & $3812-3833 / 3932-3953$ \\
\hline
\end{tabular}

${ }^{a}$ Numbering system refers to the partial SCAP cDNA sequence, KIAA0199

Cloning of the human SCAP gene

A genomic region of over $110 \mathrm{~kb}$ containing the entire human SCAP gene was cloned in two overlapping PAC clones. The length of the $S C A P$ gene is over $30 \mathrm{~kb}$, which is about eight times the size of $S C A P$ cDNA. It consists of 23 exons interrupted by 22 introns (Table 2, Fig. 2A). Exon 1 was the smallest at $44 \mathrm{bp}$. Other exons ranged from 81 to $523 \mathrm{bp}$. Exons 4-16 and exons 17-23 clustered in the $10.3-\mathrm{kb}$ and $4.2-\mathrm{kb}$ regions, respectively, while exons 1,2 , and 3 were each interrupted by introns over $8 \mathrm{~kb}$ in size. Sequences at the exon-intron boundaries for all 22 introns are 
Fig. 1. A Nucleotide sequence of the $5^{\prime}$ region of sterol regulatory element binding protein cleavage-activating protein $(S C A P)$ transcripts and deduced amino acid sequences KIAA0199, Partial human SCAP cDNA sequence. B Nucleotide sequence of the $5^{\prime}$ flanking region of the SCAP gene. The uppercase letters refer to the exon 1 sequence. Nucleotide 1 is assigned to the putative transcription initiation site. Putative binding motifs for Sp1, AP2, SREBP-1, and HNF3B are indicated by underlines
A

\section{1}

GCCGCCGCCGCCGCCGCGCAGCTTGGGAGGTGCTGCCACAGGTACCTGCACATGTTGTT

60

CTTTGTCAGTGCTGTCAAGTGTGTGCCAGGGTGATCCATGGTCACTTTCCGGGATGGCA KIAA0199

120

GCAAGGTGACTTCGGCTGAGGATGACCCTGACTGAAAGGCTGCGTGAGAAGATA

$$
\begin{array}{llllllllllll}
M & T & L & T & E & R & L & R & E & K & I
\end{array}
$$

B

aggcttacctctgacacaagacc

-1020 tgggtacagcaagggcatgcagtagcatgatcaaagtcccccagagtggtccgggcag

-960 gtctctagttgggccagagetgggcaggtggggacctgtgtttccctcgaggggaggca $\mathrm{Sp} 1$

-900 cctcccettcccettctgtgaggccctgtaacaagacctacctcggattttcaggaggg

-840 caaatgcgaggacatgtacaataccagctccgcaactgacacctagtaaacagtgaacg

-780 agctgttgctattataacaaatacctgttccctgtggaaaatggttaaatgtcaactta HNF3B

-720 gctttaaatgtctatagggaaactagttttatggacattatttattcttctcatctgc

-660 tttgcagtgtatctcggcccagctgcttctaattttttgccattataaaacagggaaca

-600 gagcatcttgtgcagggtgggttttttgttttttgtctcactgtggcctcgacctcccg ADD1/SREBP-1

-540 getcaggtgatcctcctacctcagcctcctgagtagctgggaccacaggtgcgcgccac

-480 acagccggctaattaattttacttgtggagacggaggtctcctacgttgcccaagttgg

-420 ctctaactcctcggctcaagcgatcttcgcgccttggactcccacagtgttgggattac

-360 accgcgagccaccgtgcccggctttctgcaagttcttgatgaccgatgagagccggtgg

-300 cccaaacccggegggecctaacccggettcacgetccgcccggcceggeccggeccgge

-240 gtccatacttccctccggtgtccaccagagggcgaacgggagacgcgaatgtggttcga AP2 Sp1

-180 tacgcatgcgcacgccgctgggcgcacgtgcggagggcggcggggcgggagggtaaagg Spl

-120 aggaggtgagaggtgaaggggegggcacccggcggccaggagagagagggagggegcca Sp 1

-60 gcaccggactgcgggccgagagcgcgcacgccgegetccgeccetgetgccgccccegt

+1 GCCGCCGCCGCCGCCGCGCAGCTTGGGAGGTGCTGCCACCACAGgtacCgacacgCggg

+61 getcagggegcetgccegcgggccccagctcgaccccagccgegtggagetgggagtt compatible with the consensus sequence for the splicing junctions, including AG-GT (Mount 1982).

Comparison of the gene sequence with the human cDNA sequence revealed that exon 1 and the $5^{\prime}$ half of exon 2 encode the $5^{\prime}$ UTR, while the $3^{\prime}$ portion of exons 2 through exon 22 encodes the coding region, and exon 23 encodes both the carboxy-terminal coding region and the 3'UTR (Fig. 2B). Exon 23 possesses a polyadenylation site preceded by a polyadenylation signal. 
Fig. 2. A Genomic structure of the human SCAP gene. B Relationship between exon organization and functional domains of SCAP. A translation initiation codon $(A T G)$ is present in exon 2 and a translation stop codon $(T G A)$ is present in exon 23. TM, Transmembrane region; $W D$, Trp-Asp
A

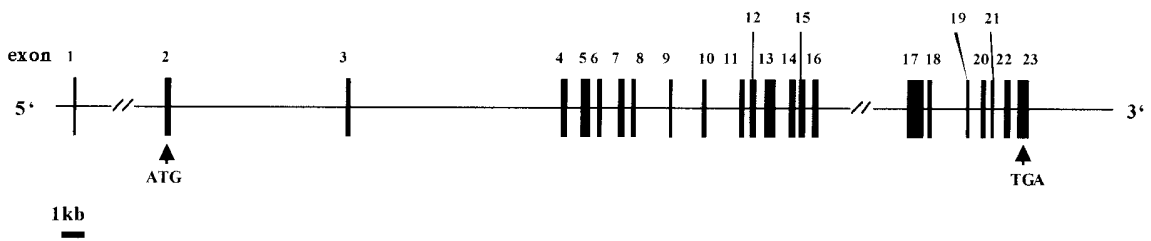

B

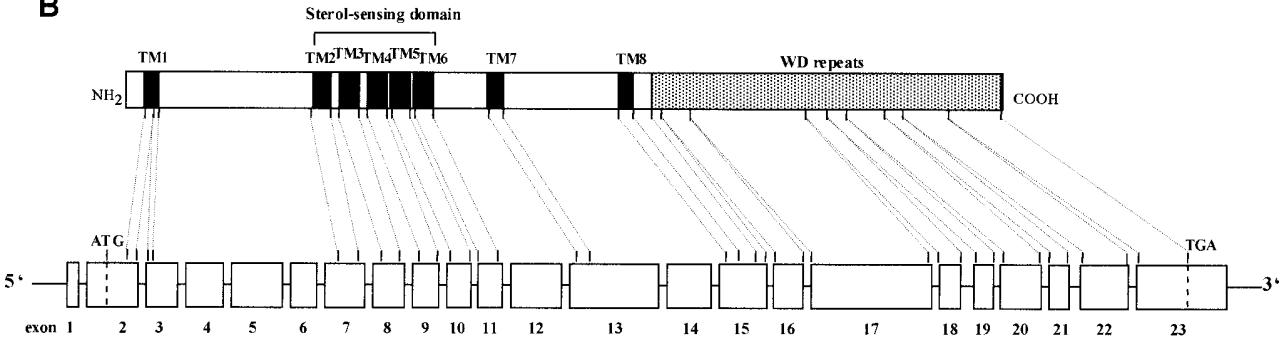

Chromosomal mapping of the $S C A P$ gene

A PAC genomic clone was used as a probe to localize the $S C A P$ gene by FISH on metaphase chromosomes. Clear fluorescent signals were visualized on chromosomal band 3p21.3 (Fig. 3). We previously isolated a CA-repeat polymorphism at the SCAP locus and linked it to DNA markers on $3 p$ by radiation hybrid mapping, using Stanford G3 hybrid panels (Nakajima et al. 1999). Sequence analysis of the $S C A P$ gene in the present study showed that this CA-repeat polymorphism was present in intron 2 of the SCAP gene (data not shown). FISH analysis carried out in the present study refined the localization of the human SCAP gene to chromosomal band 3p21.3.

Exon organization and protein domains

Figure 2B shows the relationship between exon organization and protein domains predicted previously (Hua et al. 1996). The introns interrupt the protein coding sequence in such a way that many of the protein segments are encoded by distinct exons, as shown in Fig. 2B. The NH2- terminal domain of SCAP is predicted to contain eight membranespanning regions which are encoded by exons $2,3,7,8,9,10$, 11,13 , and 15, respectively. Exons 7-11 encode the sterolsensing domain comprising membrane spanning region 2-6 (Hua et al. 1996). This region shows sequence resemblance to putative sterol-sensing domains in three other proteins: 3-hydroxy-3-methyl-glutaryl coenzyme A (HMG-CoA) reductase, Niemann-Pick $\mathrm{C} 1$ protein, and the morphogen receptor Patched (Carstea et al. 1997; Loftus et al. 1997). A D443N mutation in the sterol-sensing domain of SCAP blocks responsiveness of SCAP to intracellular cholesterol levels (Hua et al. 1996). Transgenic mice that express this type of mutant SCAP in their livers developed enlarged livers that were engorged with cholesterol and triglycerides (Korn et al. 1998). Exons 15-23 encode the hydrophilic carboxy-terminal domains that contain four copies of a motif called the WD repeats (Neer et al. 1994). This domain is predicted to interact with and regulate SREBP and the site-1 protease (Hua et al. 1996).

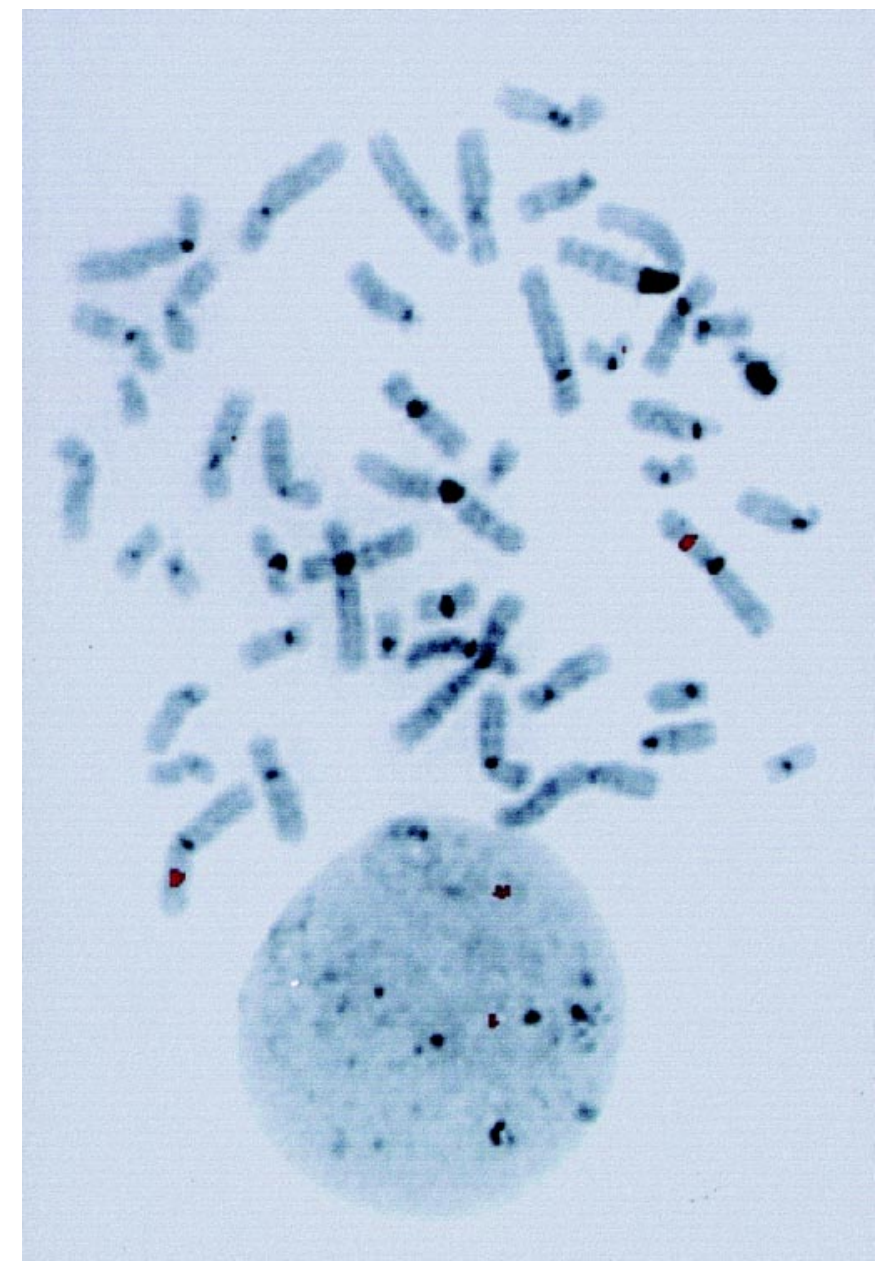

Fig. 3. Chromosomal localization of human $S C A P$ gene to $3 \mathrm{p} 21.3$ by fluorescence in situ hybridization on metaphase chromosomes

Sequence of the $5^{\prime}$-flanking region of the SCAP gene

The nucleotide sequence of the $5^{\prime}$-flanking region of the $S C A P$ gene is given in Fig. 1B. The putative promoter sequence of the $S C A P$ gene was examined with the Transcrip- 
tion Element Search Software (TESS) on the www at the http://agare. humgen.upenn.edu/utess/tess to identify any transcription factor binding sites. The nucleotide sequence of the 5'-flanking region comprises a high G/C-rich region and contains Sp1 sites and an AP2 site. No CAAT or TATA box was present up in the $5^{\prime}$-flanking region of the $S C A P$ gene. These features are characteristic of the promoters of housekeeping genes (Dynan 1986). Interestingly, an ADD1/SREBP-1 site (Yokoyama et al. 1993; Kim et al. 1995) was identified in the $5^{\prime}$-flanking region of the SCAP gene. The SREBPs are a family of three closely related membrane-bound transcription factors that activate the genes for the synthesis of cholesterol and unsaturated fatty acids and their uptake from plasma. The SREBPs regulate the transcription of genes encoding several enzymes in the cholesterol biosynthetic pathway, including HMG CoA reductase, HMG CoA synthase, farnesyl diphosphate synthase, and squalene synthase (Goldstein and Brown 1997; Osborne 1995; Guan et al. 1995; Ericsson et al. 1996; Vallett et al. 1996). The SREBPs also regulate the LDL receptor, which supplies cholesterol through receptor-mediated endocytosis (Brown and Goldstein 1997; Kim and Spiegelman 1996; Yokoyama 1993). The transcriptional regulation by SREBP-1 has a central role in lipid metabolism. SCAPstimulated proteolysis releases active fragments of SREBPs from the membranes of the endoplasmic reticulum and allows them to enter the nucleus (Hua et al. 1996). Transcriptional regulation of the SCAP gene via SREBP-1 may be crucial in the regulation of lipid metabolism, but its functional significance remains to be determined. Sp1 sites are present in the $5^{\prime}$-flanking region of the $S C A P$ gene. Sp1 acts synergistically with SREBPs to activate expression of the LDL receptor gene (Sanchez et al. 1995; Yieh et al. 1995).

Our data establish the basis of investigation for molecular variants in this gene that may result in alterations in plasma lipoprotein levels and/or derangement of intracellular lipid metabolism.

Acknowledgments This work was supported by a Grant-in-Aid for Scientific Research on Priority Area "Genome Science" from the Ministry of Education, Science, Sports and Culture of Japan, and by research grants for osteoporosis from the Ministry of Health and Welfare of Japan and the Novartis Foundation for Gerontological Research.

\section{References}

Brown MS, Goldstein JL (1997) The SREBP pathway: regulation of cholesterol metabolism by proteolysis of a membrane-bound transcription factor. Cell 89:331-340

Carstea ED, Morris JA, Coleman KG, Loftus SK, Zhang D, Cummings $\mathrm{C}, \mathrm{Gu} \mathrm{J}$, Rosenfeld MA, Pavan WJ, Krizman DB, Nagle J, Polymeropoulos MH, Sturley SL, Ioannou YA, Higgins ME, Comly M, Cooney A, Brown A, Kaneski CR, Blanchette-Mackie EJ, Dwyer NK, Neufeld EB, Chang TY, Liscum L, Strauss III JF, Ohno K, Zeigler M, Carmi R, Sokol J, Markie D, O'Neill RR, van Diggelen OP, Elleder M, Patterson MC, Brady RO, Vanier MT, Pentchev PG, Tagle DA (1997) Niemann-Pick C1 disease gene: homology to me- diators of cholesterol homeostasis. Science 277:228-231

Dynan WS (1986) Promoters for house-keeping genes. Trends Genet 2:196-197

Ericsson J, Jackson SM, Edwards PA (1996) Synergistic binding of sterol regulatory element-binding protein and NF-Y to the farnesyl diphosphate synthase promoter is critical for sterol-regulated expression of the gene. J Biol Chem 271:24359-24364

Guan G, Jiang G, Koch RL, Shechter I (1995) Molecular cloning and functional analysis of the promoter of the human squalene synthase gene. J Biol Chem 270:21958-21965

Hua X, Nohturfft A, Goldstein JL, Brown MS (1996) Sterol resistance in $\mathrm{CHO}$ cells traced to point mutation in SREBP cleavage-activating protein. Cell 87:415-426

Kim JB, Spiegelman BM (1996) ADD1/SREBP1 promotes adipocyte differentiation and gene expression linked to fatty acid metabolism. Genes Dev 10:1096-1107

Kim JB, Spotts GD, Halvorsen YD, Shih HM, Ellenberger T, Towle HC, Spiegelman BM (1995) Dual DNA binding specificity of ADD1/ SREBP1 controlled by a single amino acid in the basic helix-loophelix domain. Mol Cell Biol 15:2582-2588

Korn BS, Shimomura I, Bashmakov Y, Hammer RE, Horton JD, Goldstein JL, Brown MS (1998) Blunted feedback suppression of SREBP processing by dietary cholesterol in transgenic mice expressing sterol-resistant SCAP(D443N). J Clin Invest 102:2050-2060

Kozak M (1987) An analysis of 5'-noncoding sequences from 699 vertebrate messenger RNAs. Nucleic Acids Res 15:8125-8148

Loftus SK, Morris JA, Carstea ED, Gu JZ, Cummings C, Brown A, Ellison J, Ohno K, Rosenfeld MA, Tagle DA, Pentchev PG, Pavan WJ (1997) Murine model of Niemann-Pick C disease: mutation in a cholesterol homeostasis gene. Science 277:232-235

Mount SM (1982) A catalogue of splice junction sequences. Nucleic Acids Res 10:459-472

Mukae N, Enari M, Sakahira H, Fukuda Y, Inazawa J, Toh H, Nagata S (1998) Molecular cloning and characterization of human caspaseactivated DNase. Proc Natl Acad Sci USA 95:9123-9128

Nagase T, Seki N, Ishikawa K, Tanaka A, Nomura N (1996) Prediction of the coding sequences of unidentified human genes. $\mathrm{V}$. The coding sequences of 40 new genes (KIAA0161-KIAA0200) deduced by analysis of cDNA clones from human cell line KG-1. DNA Res 3:724

Nakajima T, Ota N, Kodama T, Emi M (1999) Isolation and radiation hybrid mapping of a highly polymorphic $\mathrm{CA}$ repeat sequence at the SREBP cleavage-activating protein (SCAP) locus. J Hum Genet 44:350-351

Neer EJ, Schmidt CJ, Nambudripad R, Smith TF (1994) The ancient regulatory-protein family of WD-repeat proteins. Nature 371:297300

Nohturfft A, Brown MS, Goldstein JL (1998) Sterols regulate processing of carbohydrate chains of wild-type SREBP cleavage-activating protein (SCAP), but not sterol-resistant mutants Y298C or D443N. Proc Natl Acad Sci USA 95:12848-12853

Osborne TF (1995) Transcriptional control mechanisms in the regulation of cholesterol balance. Crit Rev Eukaryot Gene Expr 5: 317-335

Sanchez HB, Yieh L, Osborne TF (1995) Cooperation by sterol regulatory element-binding protein and $\mathrm{Sp} 1$ in sterol regulation of low density lipoprotein receptor gene. J Biol Chem 270:1161-1169

Tsukamoto K, Ohta N, Shirai Y, Emi M (1998) A highly polymorphic CA repeat marker at the human interleukin 6 receptor (IL6R) locus. J Hum Genet 43:289-290

Vallett SM, Sanchez HB, Rosenfeld JM, Osborne TF (1996) A direct role for sterol regulatory element binding protein in activation of 3hydroxy-3-methylglutaryl coenzyme A reductase gene. J Biol Chem 271:12247-12253

Yieh L, Sanchez HB, Osborne TF (1995) Domains of transcription factor Sp1 required for synergistic activation with sterol regulatory element binding protein 1 of low density lipoprotein receptor promoter. Proc Natl Acad Sci USA 92:6102-6106

Yokoyama C, Wang X, Briggs MR, Admon A, Wu J, Hua X, Goldstein JL, Brown MS (1993) SREBP-1, a basic-helix-loop-helix-leucine zipper protein that controls transcription of the low density lipoprotein receptor gene. Cell 75:187-197 